\title{
ENIERQY $\mathrm{Y}$
}

Office of

ENERGY EFFICIENCY \&

RENEWABLE ENERGY

\section{Financing Federal Microgrids}

Rachel Shepherd (FEMP), Chuck Kurnik (NREL), Phil Voss (NREL)

October 14, 2020

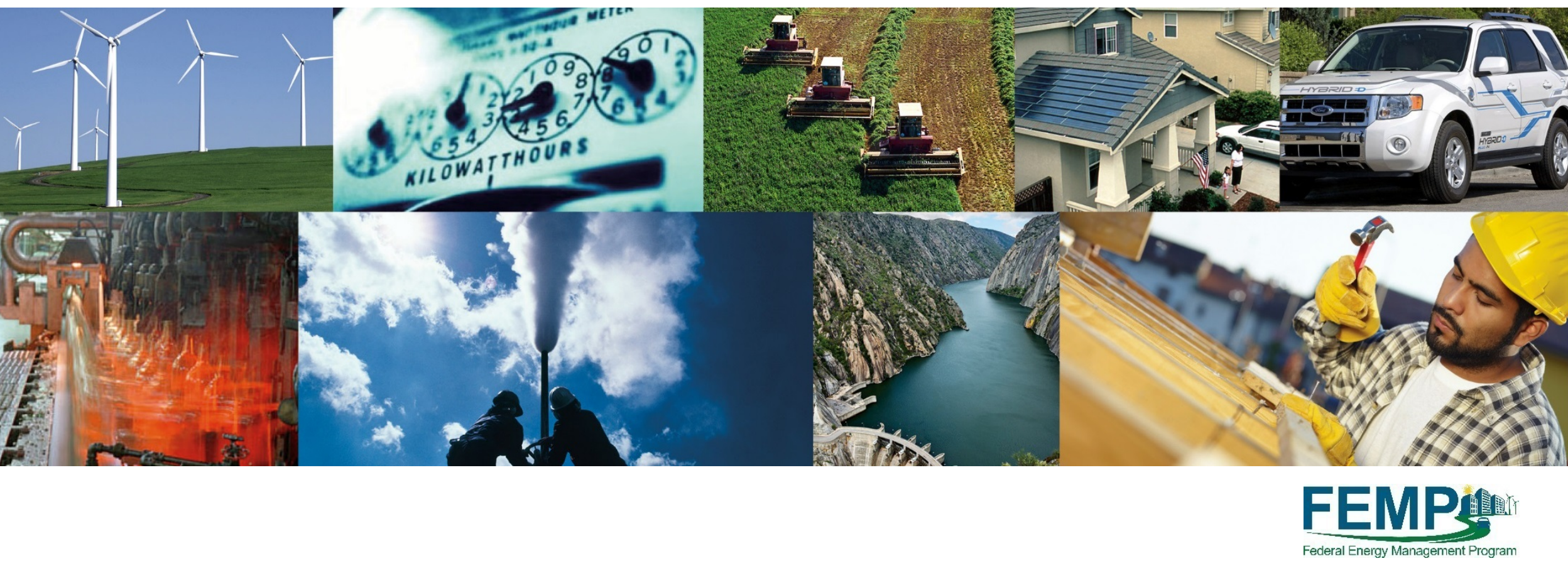




\section{Agenda and Team}

\section{Agenda}

I. $\quad$ FEMP Support

II. What is a Microgrid?

III. Implementation Considerations

IV. Procurement Options

V. Case Studies and Resources

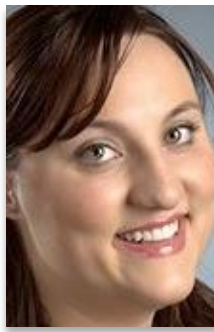

Rachel Shepherd

FEMP, Program Lead

rachel.shepherd@ee.doe.gov

202-586-9209

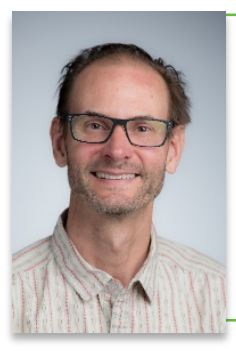

Chuck Kurnik

NREL, Senior Engineer chuck.kurnik@nrel.gov 303-275-4374

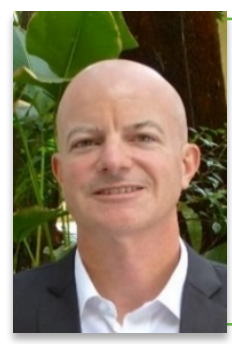

Phil Voss

NREL, Senior Project Leader

philip.voss@nrel.gov

303-384-7245 


\section{FEMP's Purpose}

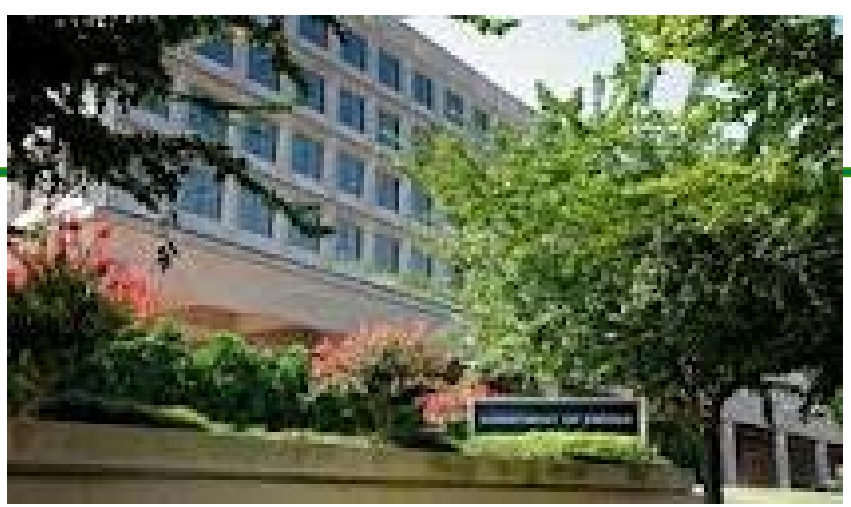

The U.S. Department of Energy's Federal Energy Management Program works with key individuals to accomplish energy change within organizations by bringing expertise from all levels of project and policy implementation to enable federal agencies to meet energy-related goals and provide energy leadership to the country. 


\section{FEMP's Distributed Energy Program}

FEMP's Distributed Energy (DE) Program facilitates the implementation of cost-effective on-site renewable energy, energy storage, and combined heat and power technologies for federal agencies.

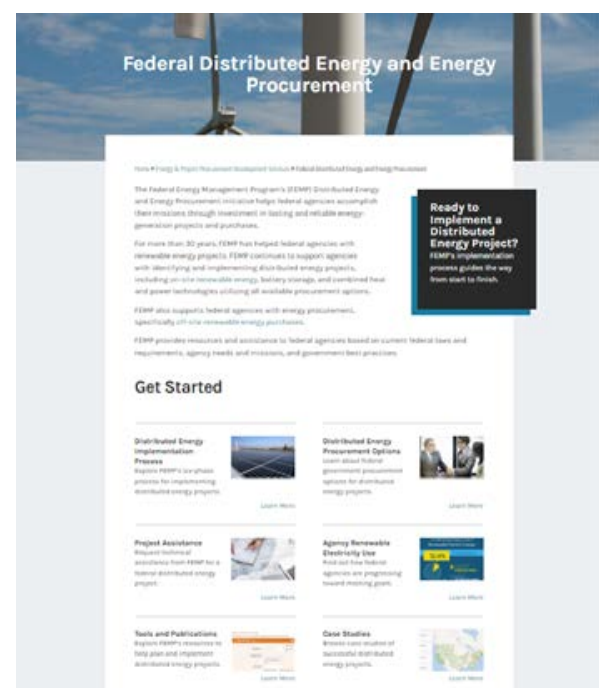

FEMP's Distributed Energy Program Website

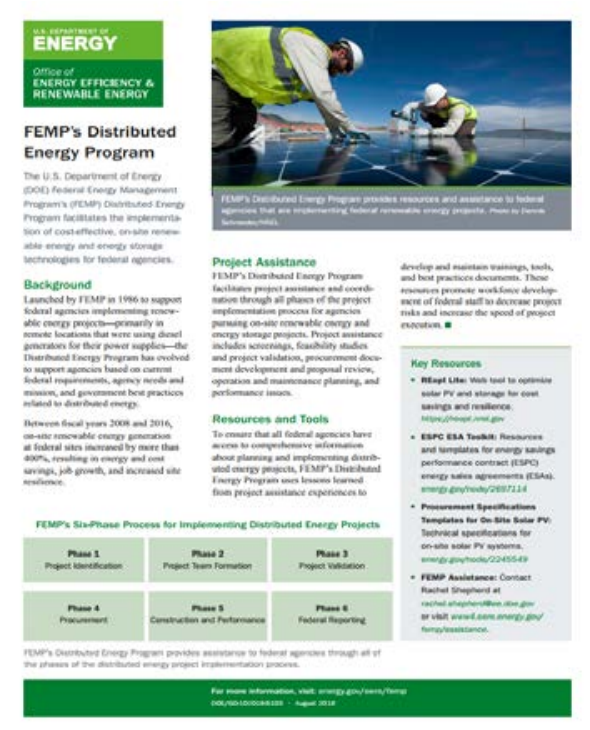

FEMP's Distributed Energy Program Factsheet

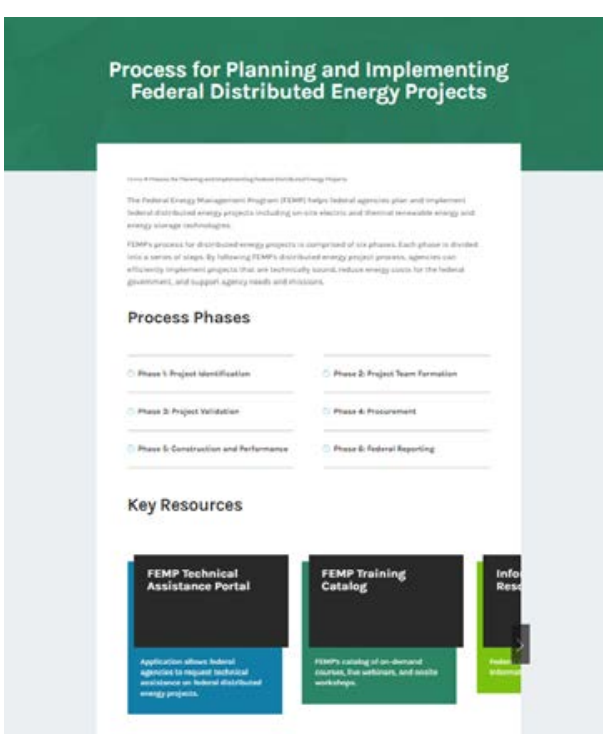

FEMP's Distributed Energy Implementation Process Website 


\section{FEMP's Technical Resilience Navigator}

The Technical Resilience Navigator (TRN) helps users assess risk to a site's critical functions from energy and water utility disruptions and prioritize solutions that reduce risk.

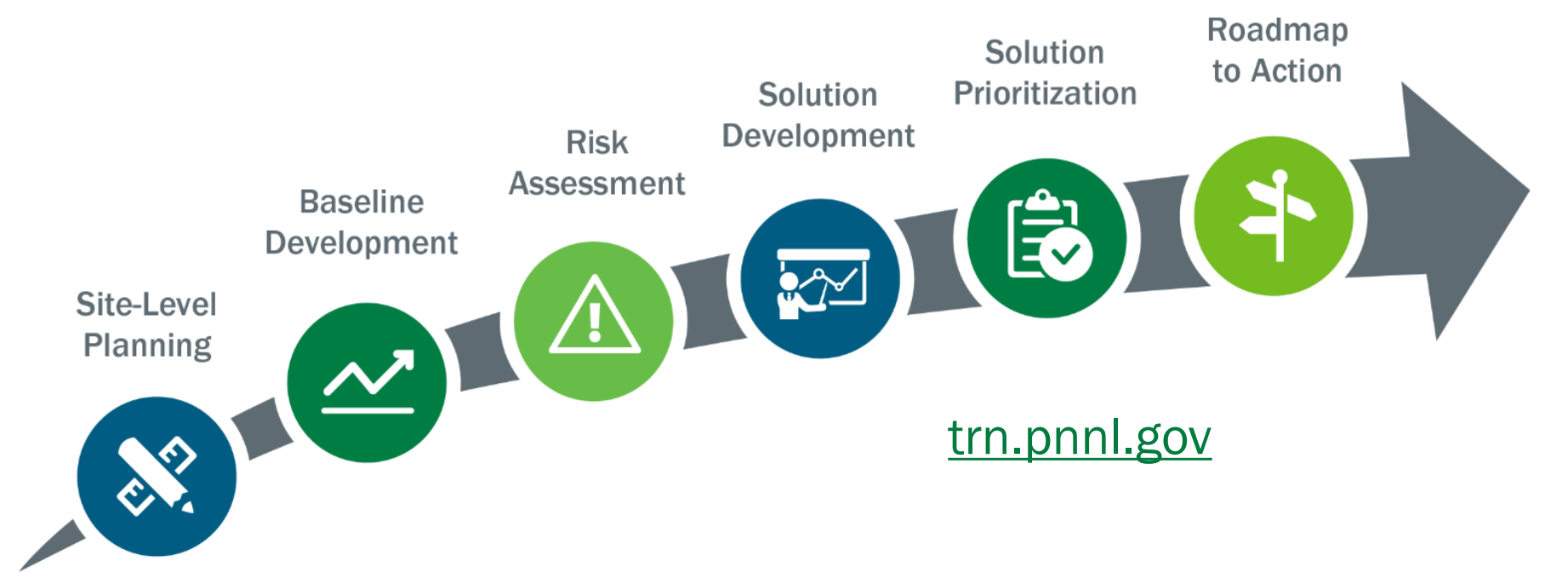

\footnotetext{
Key Outcomes

$>\quad$ Identify site hazards and vulnerabilities in energy \& water systems, operations, and plans

$>$ Establish risk from different sources, and how solutions reduce risk

$>$ Better integrate planning for energy and water management, continuity of operations, other site priorities
} 


\section{Distributed Energy as Part of a Potential Resilience Solution}

Distributed energy (renewable energy, storage, and combined heat and power, backup generators) can contribute to sites' ability to anticipate, prepare for, and adapt to changing conditions and to withstand, respond to, and recover rapidly from disruptions by:
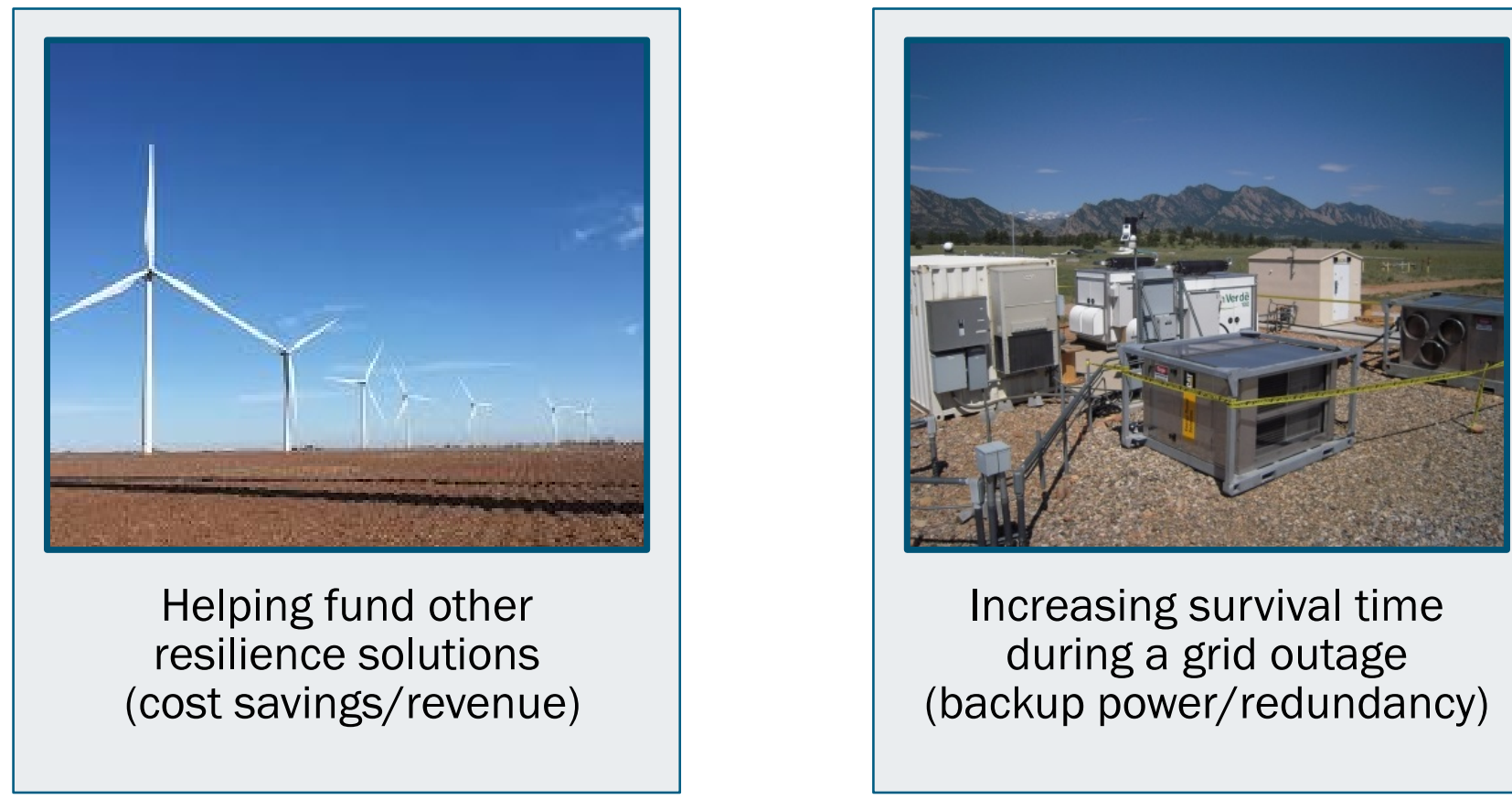

Increasing survival time during a grid outage (backup power/redundancy) 


\section{Potential DE Solutions to Enhance Resilience}

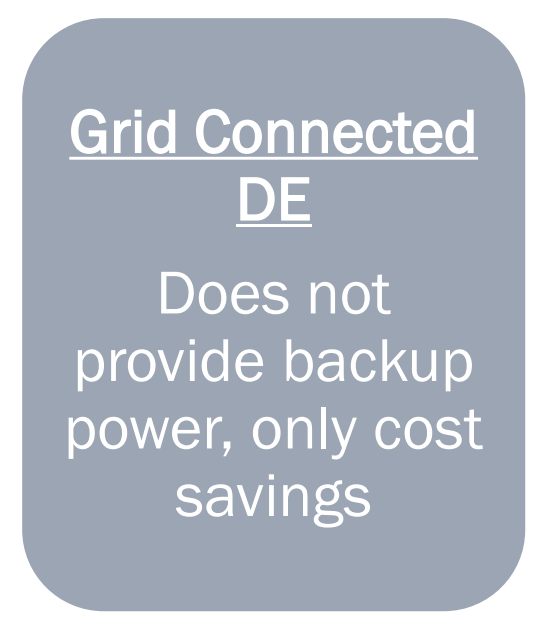

$\frac{\text { Microgrid-Ready }}{\mathrm{DE}}$
Includes low/no
cost capabilities
to facilitate
integration of DE
into a future
microgrid

DE and Energy
Storage
Can provide cost
savings /
revenue and be
configured to
provide backup
power (often
building-level)

\section{Microgrid}

Can provide cost savings / revenue and serve buildings, multiple loads, or entire site

\section{Increased Ability to Enhance Resilience}




\section{Financing Federal Microgrids}

FEMP technical report:

Financing Microgrids in the Federal Sector

- What is a Microgrid?

- Should my Agency Pursue a Microgrid?

- Economic and Technical Considerations

- Procurement Options

ENARGY

Office of
ENERGY EFFICIENCY \&
RENEWABLE ENERGY
Financing Microgrids in the Federal Sector 


\section{What is a Microgrid and How Can it Help?}

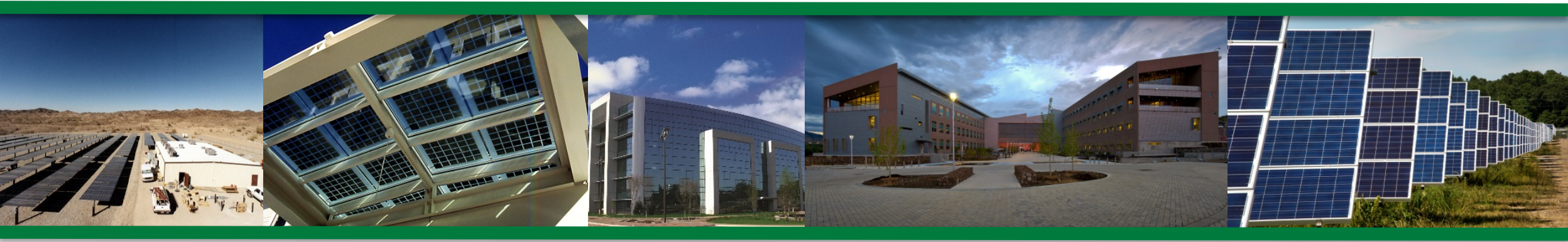




\section{What is a Microgrid?}

A group of interconnected loads and distributed energy resources within clearly defined electrical boundaries that acts as a single controllable entity with respect to the grid, and can operate in both grid-connected or island-mode (DOE 2011).

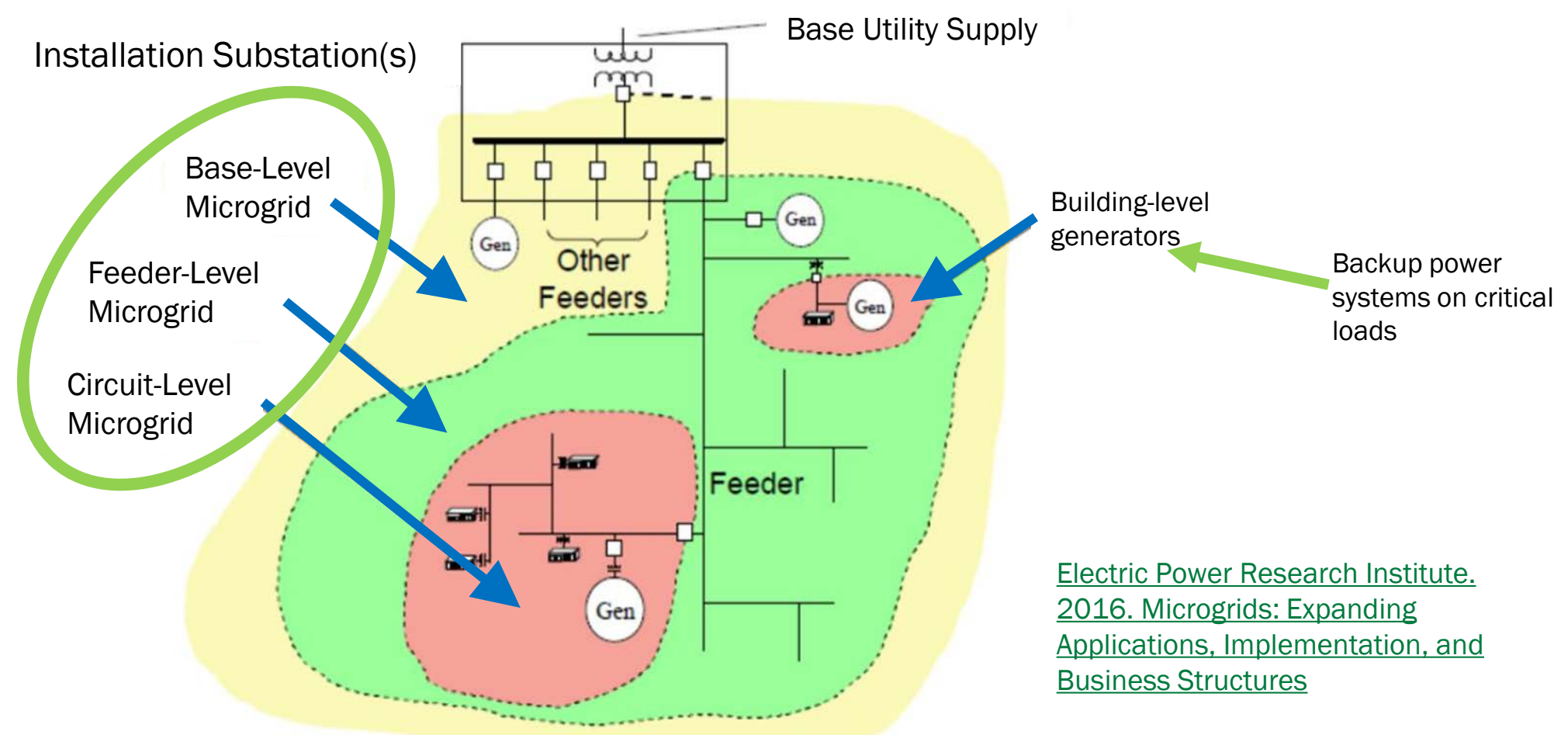




\section{Microgrids are Complex Systems}

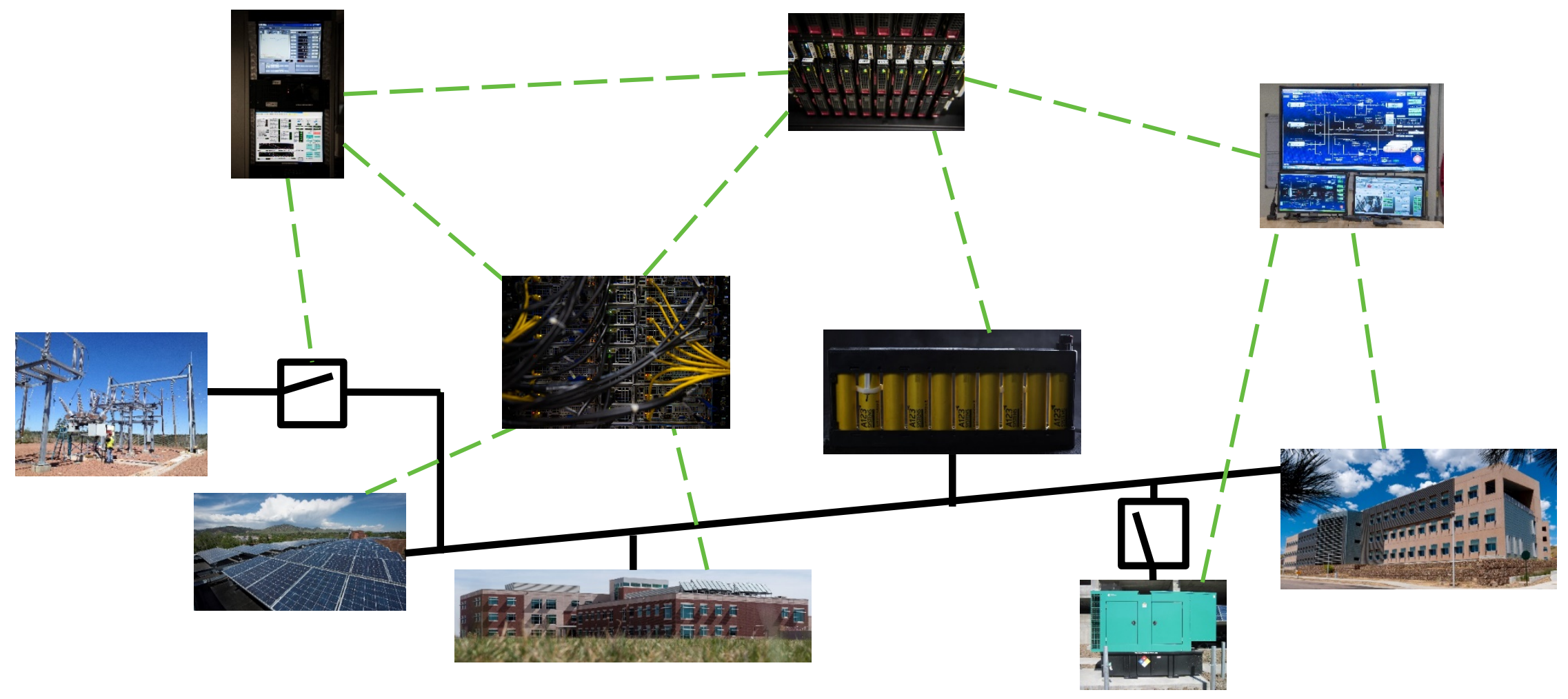




\section{Gaps Microgrids May Address}

- Energy use optimization and utility reliability

- Demand response savings

- SAIDI

- SAIFI
- Resilience vulnerabilities

- Critical energy \& water systems

- Continuous mission operations

- Life safety
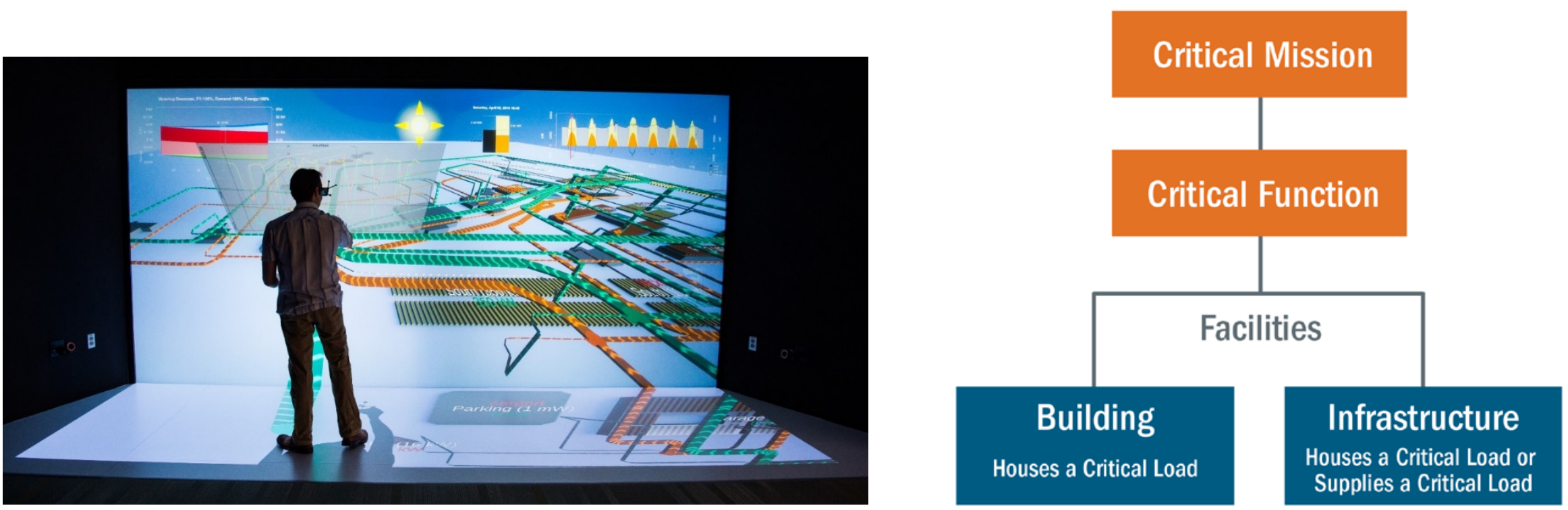


\section{Technical Considerations}

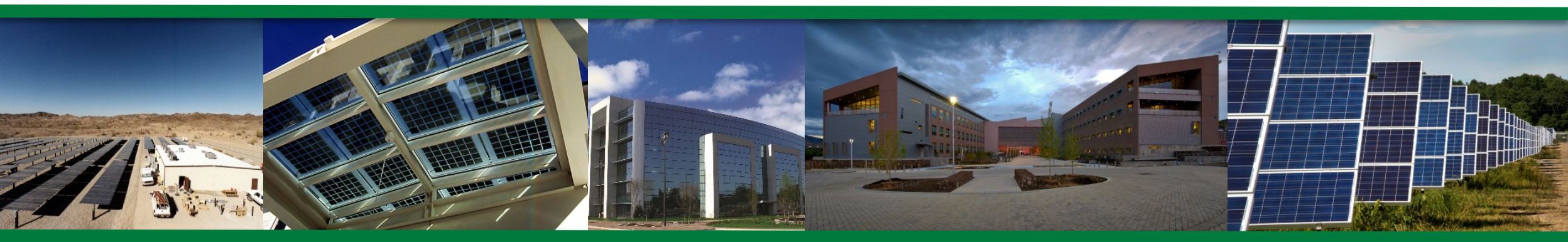




\section{DE Assets}

\section{Synchronous Generators}

- Combined Heat \& Power

- Backup Generators

\section{Microgrid-Ready PV}

- Smart inverter

- Additional space

\section{RE + Battery}

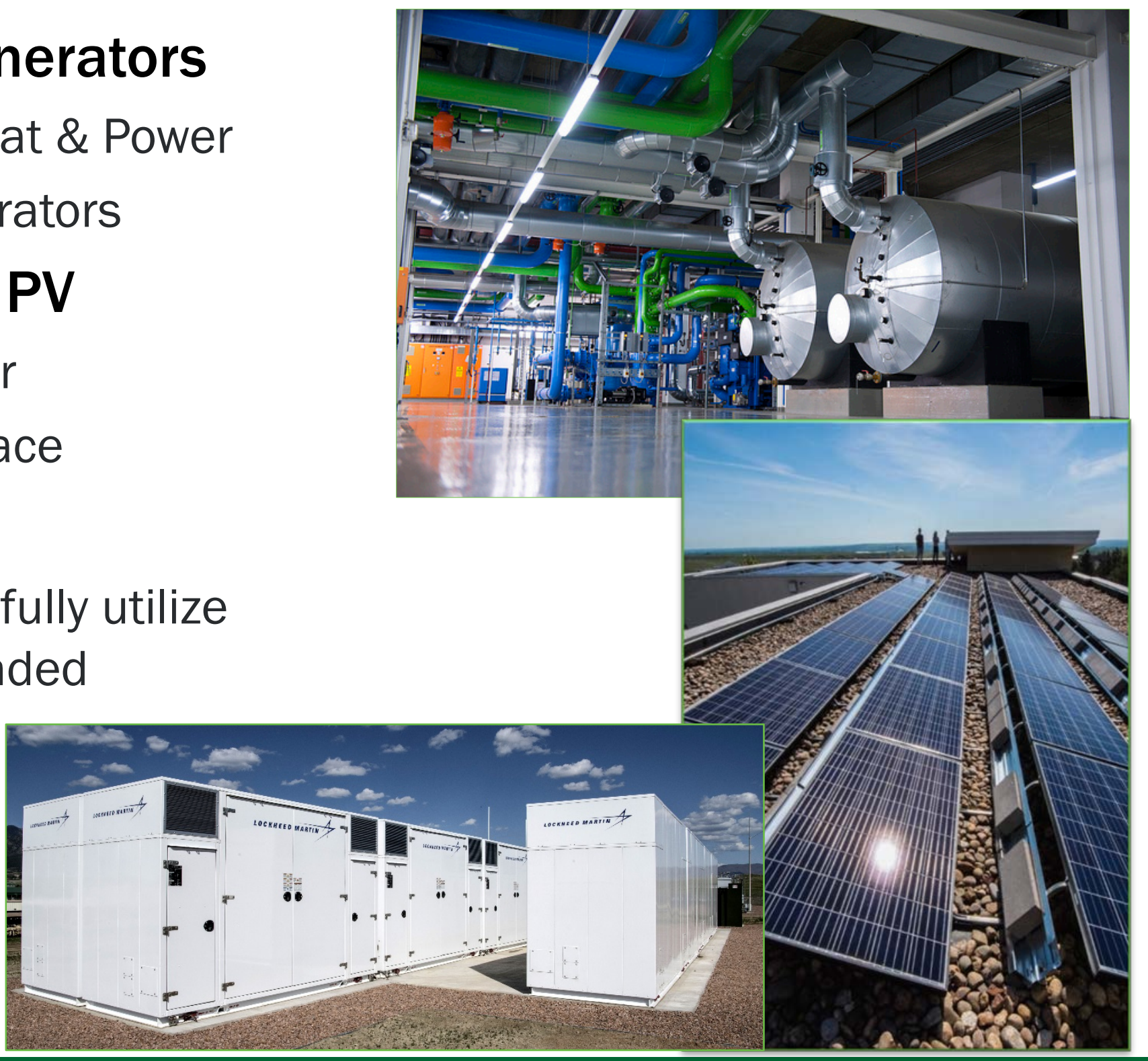

- Necessary to fully utilize $\mathrm{RE}$ while islanded 


\section{Phased Implementation}

- Single project is ideal approach

- Multiple implementation phases may be required due to cost

- Well-defined concept needed

- Plan for future modifications, expansion, functionality, use cases

- Lessons learned incorporated into future phases

- Risk mitigation

- Each phase or project should stand on alone, but be "microgrid ready" for integration into system

- Commission final result as a system 


\section{Potential DE Solutions to Enhance Resilience}

\section{Grid Connected \\ DE}

Microgrid-Ready DE

DE and Energy Storage

Microgrid

\begin{tabular}{|c|c|c|c|}
\hline Backup Power & $\begin{array}{l}\text { No backup power, but could } \\
\text { support a future microgrid }\end{array}$ & $\begin{array}{l}\text { Can be configured to provide } \\
\text { backup power }\end{array}$ & $\begin{array}{l}\text { Backup power for multiple loads } \\
\text { or an entire site }\end{array}$ \\
\hline Upfront Cost & $\begin{array}{l}\text { Slightly higher cost than grid- } \\
\text { connected (for equipment, } \\
\text { space, communications) }\end{array}$ & $\begin{array}{l}\text { Higher cost (for storage and } \\
\text { controls) }\end{array}$ & $\begin{array}{l}\text { Much higher cost (for additional } \\
\text { required equipment, controls, } \\
\text { and communication) }\end{array}$ \\
\hline Cost Savings & Lowers utility bills & $\begin{array}{l}\text { Could lower utility bills with } \\
\text { potential for additional savings } \\
\text { and/or revenue streams }\end{array}$ & $\begin{array}{l}\text { Lowers utility bills with potential } \\
\text { for additional savings and/or } \\
\text { revenue streams }\end{array}$ \\
\hline Complexity* & $\begin{array}{l}\text { Fairly straight forward, requires } \\
\text { minor revisions to equipment } \\
\text { functionality }\end{array}$ & $\begin{array}{l}\text { More complex due to required } \\
\text { charge/discharge protocols } \\
\text { and other factors }\end{array}$ & $\begin{array}{l}\text { Much more complex, requires } \\
\text { isolation, communications, and } \\
\text { detailed analysis of existing } \\
\text { distribution system, } \\
\text { knowledgeable and skilled } \\
\text { operators }\end{array}$ \\
\hline
\end{tabular}

* Dependent on agency's and contractor's experience implementing DE and resilience projects 


\section{Procurement Options}

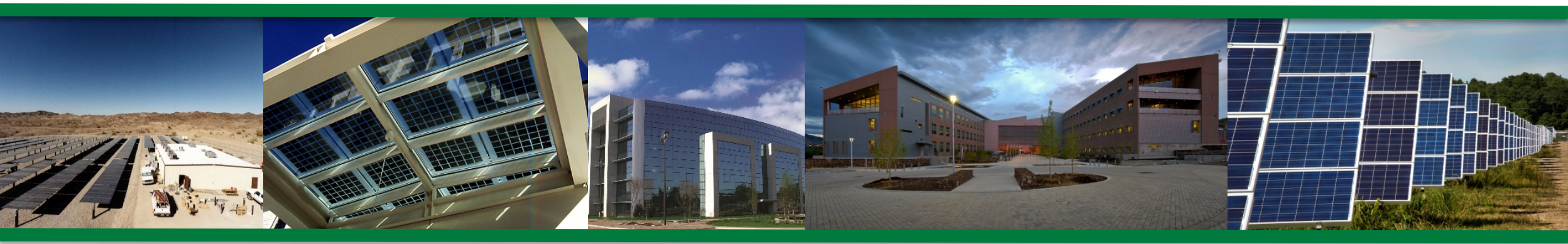




\section{Federal DE Project Procurement Options}

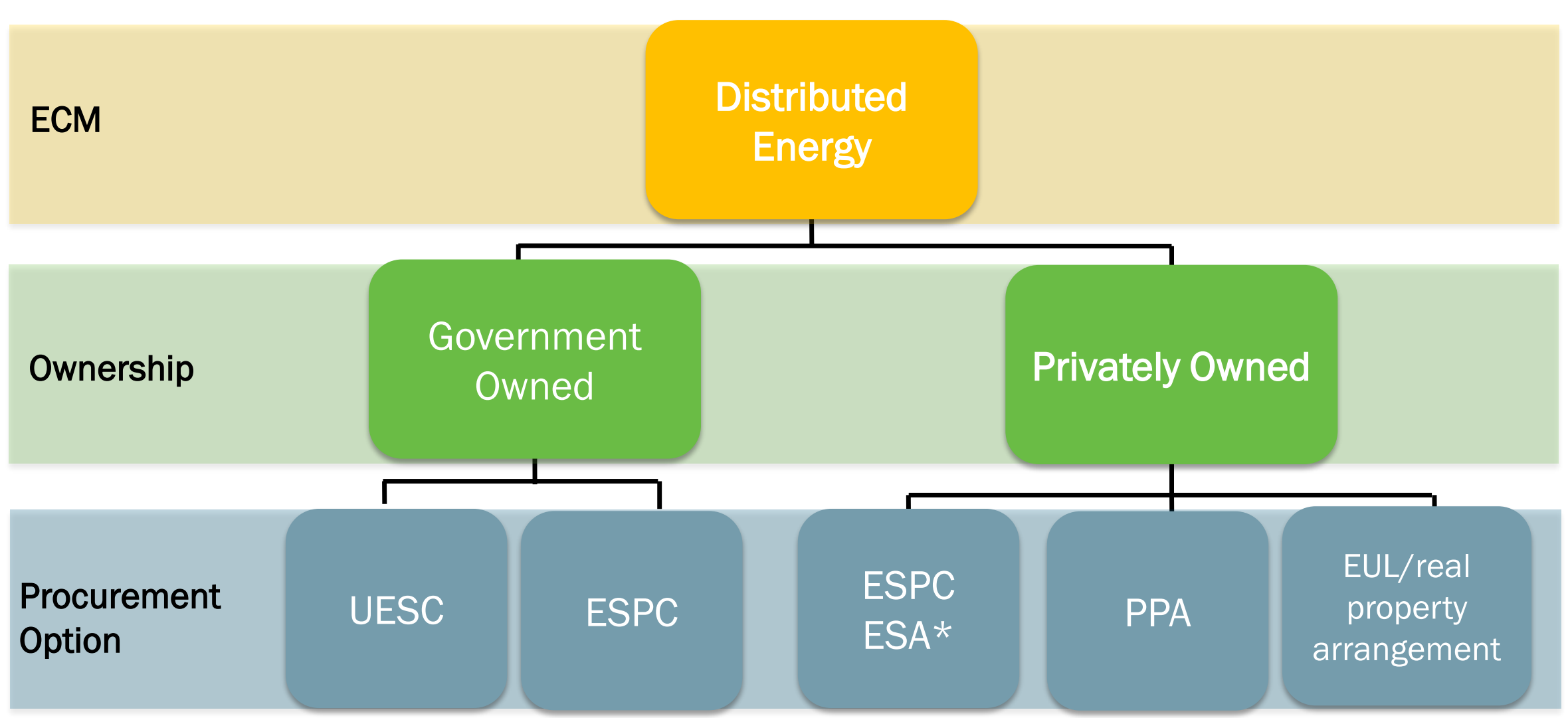

\begin{tabular}{ll|ll}
\hline \multicolumn{3}{c}{ Legend \& Abbreviations } \\
\hline ECM & Energy Conservation Measure & ESPC ESA & ESPC Energy Sales Agreement \\
UESC & Utility Energy Service Contract & PPA & Power Purchase Agreement \\
ESPC & Energy Savings Performance Contract & EUL & Enhanced Use Lease \\
\hline
\end{tabular}

*System is privately owned initially, government must retain title by end of the contract (OMB Memo requirement) 


\section{Performance Contracts are a Budget-Neutral Solution}

Reallocate the Government's Utility Bill

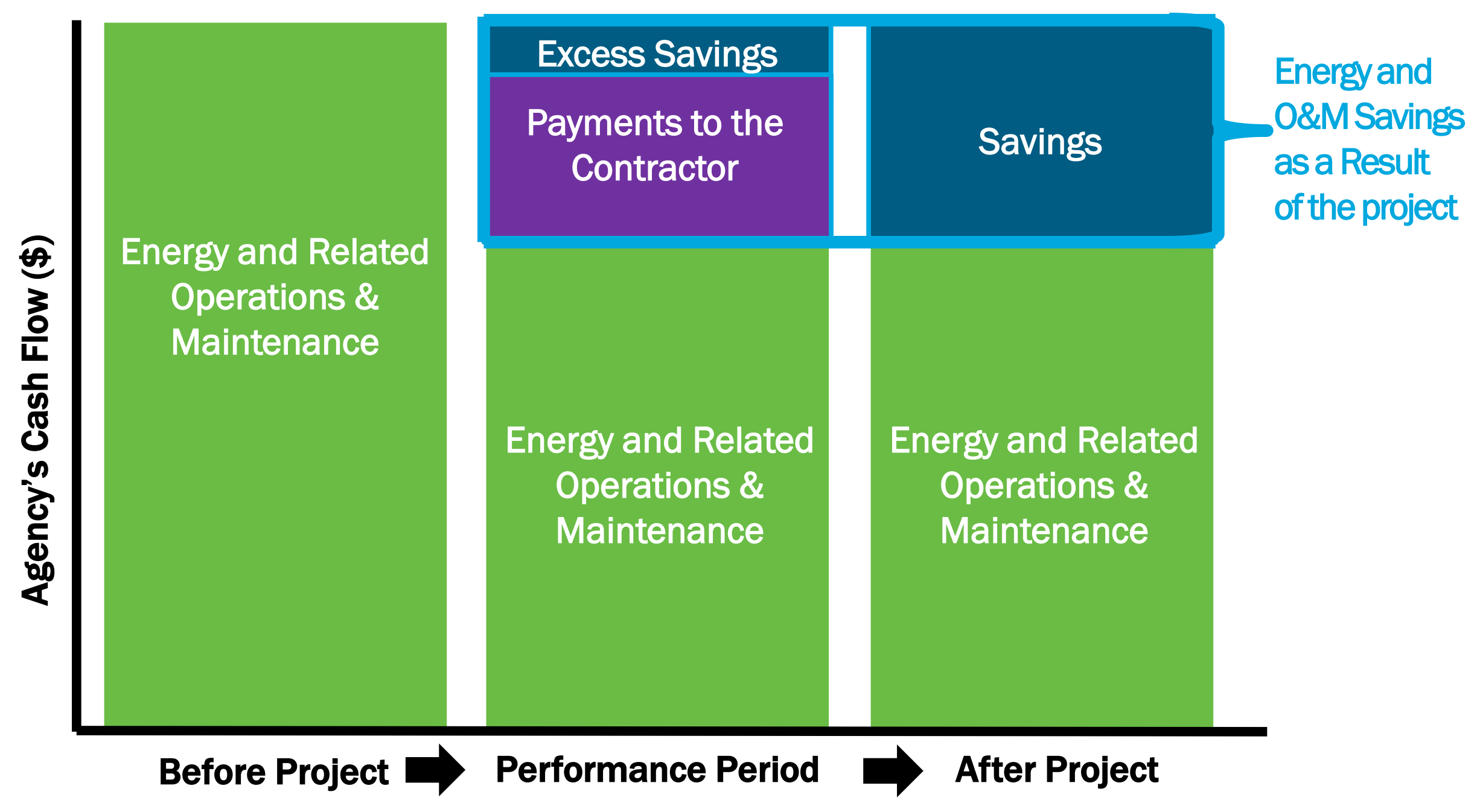




\section{Utility Energy Service Contract}

Limited-source contract between a federal agency and its serving utility for energy- and water-efficiency improvements and demandreduction services.

- Legal authority: 42 USC 8256, up to 25 years

- During contract term, payments come from resulting savings (or agency funds)*

- Performance Assurance required; guarantees are negotiable

- DE projects can be bundled with other measures

- UESCs can be executed under one of the following:

- Areawide contracts (AWCs)

- Basic ordering agreement (BOAs)

- Separate contracts

- Interagency Agreements (when working with a Federal utility)

* Unlike ESPCs, UESCs do not have a statutory annual savings requirement but must still be lifecycle cost effective. Performance assurance required for annual scoring. 


\section{Energy Savings Performance Contract}

Contract between a federal agency and an energy service company (ESCO) to procure energy conservation measures (ECMs) without additional appropriations.

- Legal authority: 42 USC $\S 8287$ et seq., up to 25 years

- Payments come from guaranteed energy cost savings

- M\&V required to validate cost savings and ECM performance

- DE projects can be bundled with other ECMs

- DE projects can be government or privately owned

- Main types of federal ESPCs:

- DOE indefinite-delivery, indefinite-quantity (IDIQ)

- DOE ENABLE

○ Site-specific/stand-alone with DOE-qualified ESCOs 


\section{ESPC Energy Sales Agreement}

Uses long-term ESPC authority for DE projects on federal buildings or land; DE is privately-owned and agency purchases the electricity.

- Similar to PPA, but implemented as ECM within an ESPC

- O\&M/repair \& replacement provided by the ESCO

- ESA ECM can be bundled with other ECMs

- Private ownership allows tax incentive benefits

- Agency must retain equipment title by end of contract

- Title transfer at fair market value

- Differences from typical ESPC:

- Payment based on kWh generation; price in $\phi / k W h$

- Maximum contract term: 20 years

- Savings accrue immediately

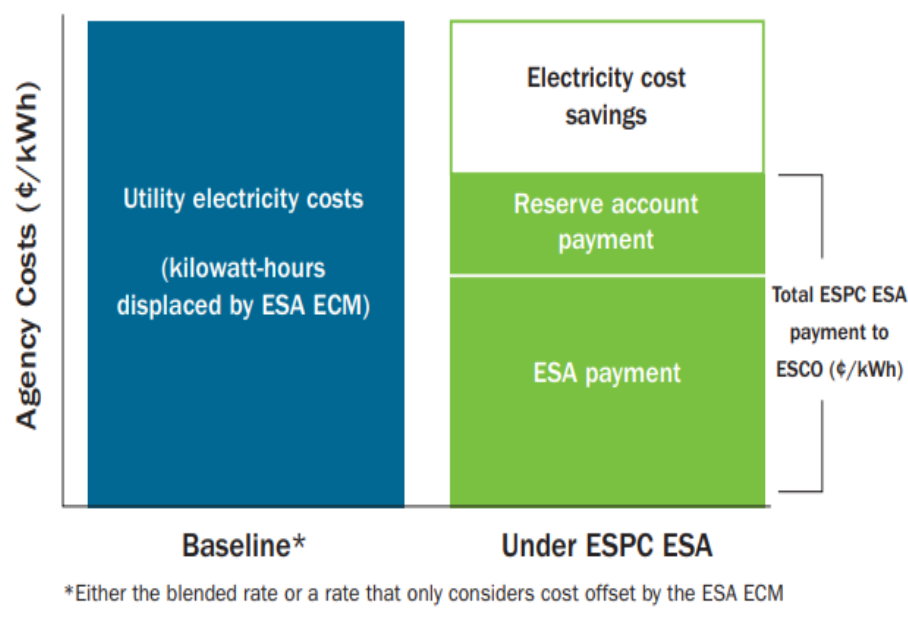




\section{Power Purchase Agreement}

Developer installs, owns, operates, and maintains DE project on federal land, and agency purchases electricity produced.

- Legal authorities:

- 40 USC 501 (FAR Part 41, GSA authority requires delegation, 10-year term)

- WAPA (20-year term, possibly longer)

- Agency may have option to purchase system at end of contract

- Developer could be any third-party, including site's serving utility company

- Stand-alone project, not bundled with efficiency ECMs 


\section{Utility Service Contract (USC)}

Bilateral agreement between a federal agency and its serving distribution utility for service connection, demand side management services, "special facilities services" or other service options.

- Legal authority: 40 USC 501 (FAR Part 41, GSA authority requires delegation, 10-year term)

- Partnership with utility

- Allows for special facilities to be financed, installed, owned, and maintained by the utility on customer side of the meter

- Payments made over time with "facilities charge," upfront agency funds, or combination

- Explore where mutually beneficial, for example:

- Savings /appropriations insufficient to cover microgrid costs

- Microgrid more cost effective than utility grid upgrade

- Other ancillary services benefit utility grid 


\section{Performance Must Be Clearly Defined}

Contract must include clear performance requirements

- Level of reliability (critical to include in contract terms)

- How much redundancy

- Which loads will be served by DE

- DE recovery and robustness

- How fast the DE can recover from an outage

- How well the DE can withstand interruptions to grid service, and for how long

- Specified damages for failures to meet performance requirements

- Table of damages for DE outages of varying lengths and frequencies 


\section{Project Development and Implementation}

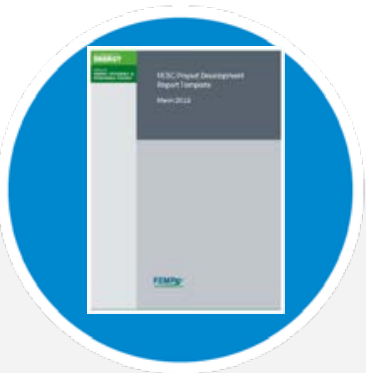

Define Project

Objectives

Priorities

Acquisition Plan

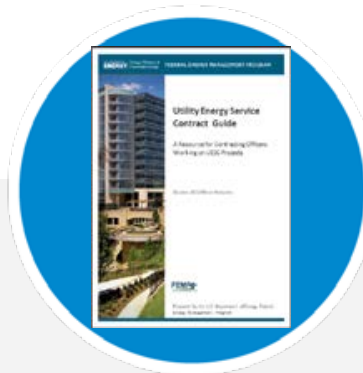

RFP

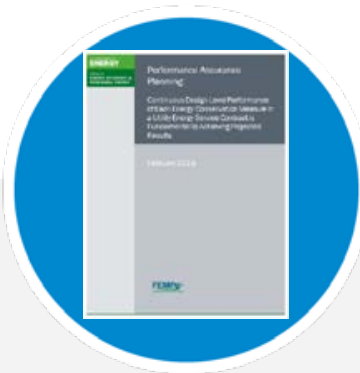

Develop Project

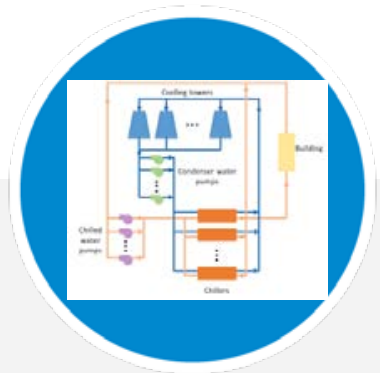

Implementation

Construction

Commissioning

Proof of

Performance

Performance Plan

Contract Award

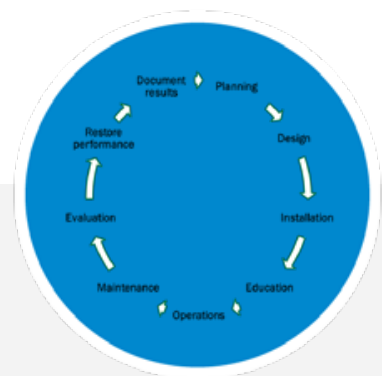

Performance

Operations, Maintenance, and Performance Assurance activities

\section{1-2 years}

* Performance Period term depends on the procurement vehicle. ESPC and UESC allow 25 years; ESPC ESAs allow 20 years; PPA and USC allow 10 years for most agencies, or more under specific circumstances 


\section{Potential Sources of Savings}

- Comprehensive project including efficiency ECMs

- Reduce critical loads

- Include ECMs with shorter payback periods

- Reduced/eliminated 0\&M expenses (e.g., replacing aging/maintenance intensive equipment)

- Other avoided costs, for example:

- CHP may obviate need for individual building boilers

- Planned on-site distribution system upgrades included in microgrid installation

- Utility savings (e.g., demand reduction, ancillary services)

- Rebates, incentives, other value streams

- Appropriations or grants may be leveraged for resilience not covered by energy savings 


\section{Potential Incentives and Value Streams}

All technology options may qualify for incentives and/or result in revenue streams while grid connected

- Potential value streams:

- Demand charge savings, energy arbitrage, demand response, ancillary services, REC sales

- Potential Incentives:

- Rebates, other state/local incentives

- Federal ITC and MACRS; state/local incentives such as property and sales tax exemptions 


\section{Federal Solar Investment Tax Credit (ITC)}

ITC for developers with tax appetite; improves PV project cost-effectiveness

- Recent legislation extended the ITC phase-down schedule by two years*

- 26\% before 2023

- $22 \%$ before 2024

- ITC amount based on "commenceconstruction" year

- See IRS Notice for additional detail*

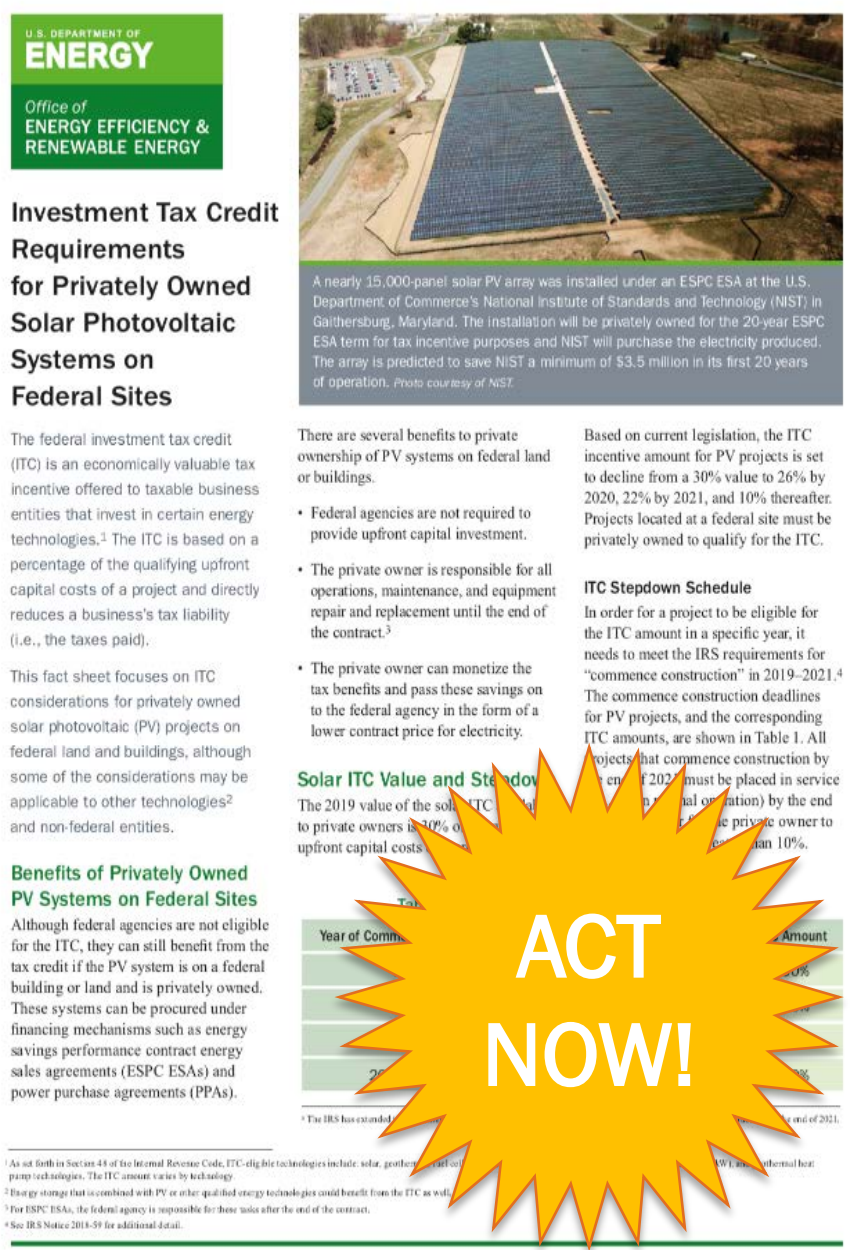

The third-party project owner should seek qualified tax advice 


\section{Summary}

- Microgrids are typically complex and expensive

- Discuss goals/needs with utility early

- Third-party financing may fund all or most microgrid components

- Leverage appropriations / incentives / value streams

- Bundle with efficiency measures

- Phased approach requires planning for future expansion, functionality, and use agreements

- FEMP assistance and resources are available 


\section{Case Studies and Resources}

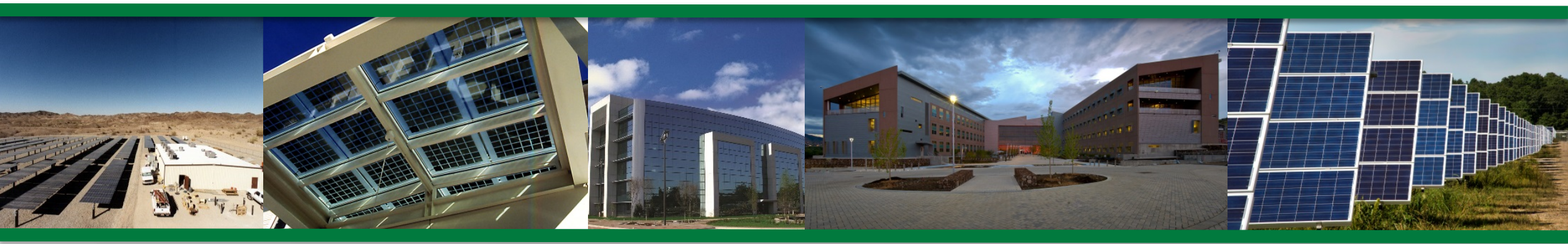




\section{FDA White Oak ESPC}

\section{FDA's Federal Research Center}

White Oak Campus (3.9 million sq. ft.)

Silver Spring, MD

\section{Project Investment Value}

\$280 million, 3-phase project with Honeywell

(Original TO award in 2010)

\section{Results}

- Campus is now five groups of interconnected buildings with shared utility infrastructure: energy efficient, secure, resilient, and capable of expanding to meet future needs

- Multifuel, integrated $55 \mathrm{MW}$ central utility plant micro-grid operates through disruptions to utility grid

- Campus has operated in island mode 80+ times since completed in 2014

\section{Annual Savings}

$\$ 52$ million avoided utility and O\&M costs

915,000 MMBtu

https://www.energy.gov/eere/femp/honeywell-helps-deliver-resiliencyand-cost-savings-food-and-drug-administrations-white 


\section{Naval Construction Battalion Center USC}

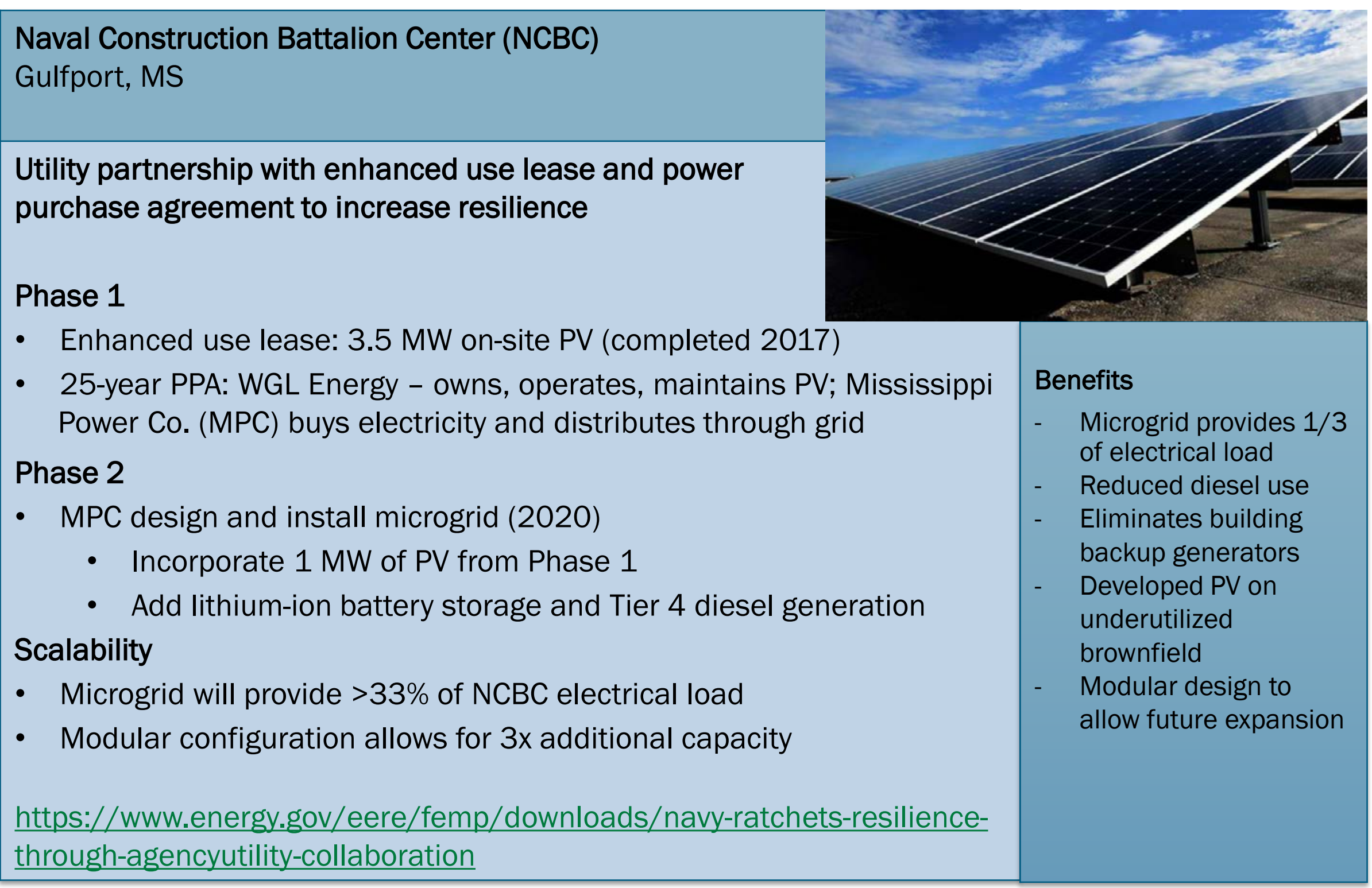




\section{FEMP Procurement Resources}

- DOE ESPC

- ESPC ESAs

- UESC

- Power Purchase Agreements (PPA)

- Financing Microgrids in the Federal Sector

- Procurement Specifications Templates for On-Site Solar Photovoltaic: For Use in Developing Federal Solicitations
Energy Savings Performance Contract Energy Sales Agreements

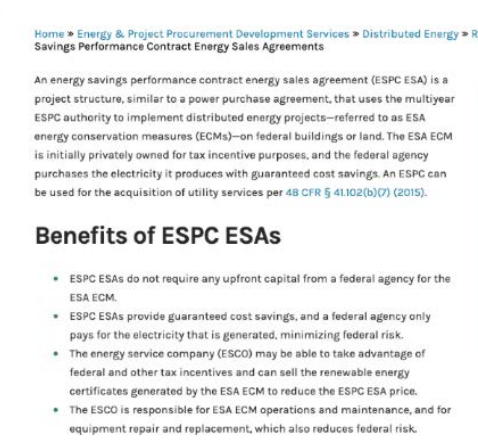

Start an ESPC ESA

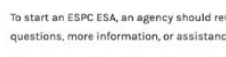

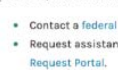

ESPC ESA Contract Vehicle Options

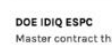

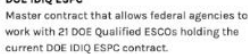

Doe Espe enuabs

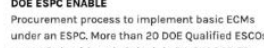




\section{FEMP Resilience Resources}

- FEMP Resilience Planning webpage

- Case studies, FEMP courses

- Technical Resilience Navigator tool

- Pre-screening for distributed energy opportunities

- Distributed Energy Resource Cybersecurity Framework (DERCF)

- Distributed Energy Technologies for $\underline{\text { Resilience }}$

Resilience Planning and Implementation

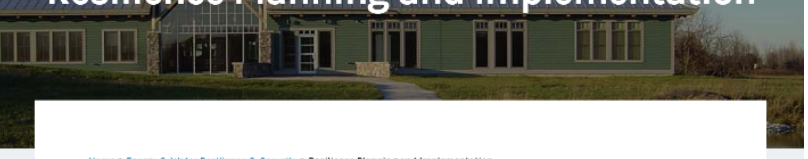

The Federal Energy Management Program (FEMP) uses a comprehensive approach to resilience planning and implementation that enables federal agencies to optimize energy and water infrastructure, ensur
mission operations.

This comprehensive approach addresses the continuity of key operations focus areas and includes

- A risk-informed methodology to identify and prioritize resilience gaps and solutions
A flexible approach that is adaptable to an organization's site-specific characteristics and data

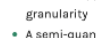

$$
\begin{aligned}
& \text { - A semi-quantitiative foundation } \\
& \text { prioritized resilience os } \\
& \text { - Documentions }
\end{aligned}
$$

Energy managers can also use FEMP's facility optimization and proje procurement development tools to support resilient critical missions in federal facilities.
Optimized facilities reduce grid load and require less backup power to maintain continuity of

\section{Resilience Planning Support}

FEMP supports resilience planning by:

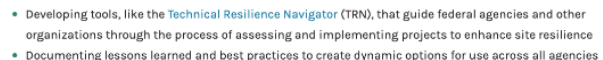

- Documenting lessons learned and best practices to create dynamic options for use across all agencies and regional plans that use pertormannce contracting as a critical component - Providing tect
approaches 


\section{DE Screening Tools \& Resources}

- NREL Tools Help Identify and Evaluate Renewable Energy Projects Factsheet

- REopt Lite

- Technology Cost and Performance Matrix

- Resource Maps

- Incentives and Utility Policies

- CHP: Technical Assistance Partnership (TAP)

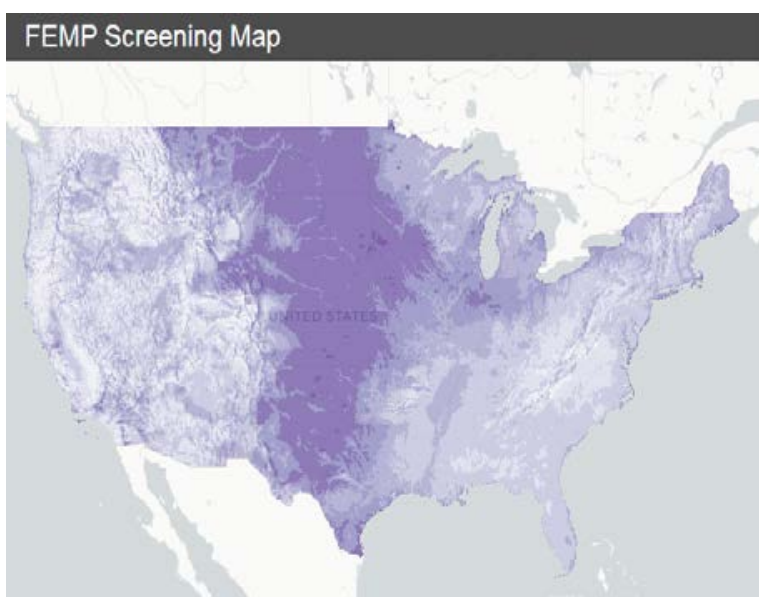

REopt Lite

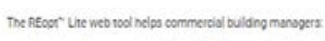

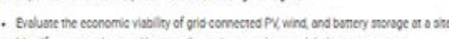

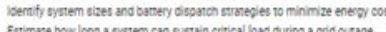

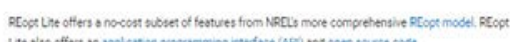

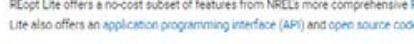

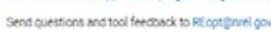

Step 0: Login and Gather Data

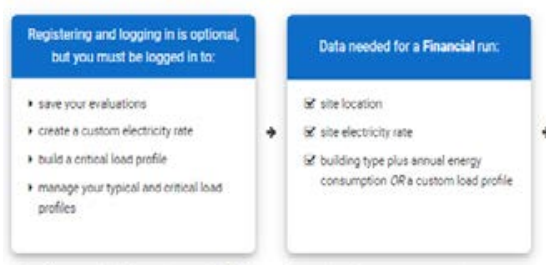

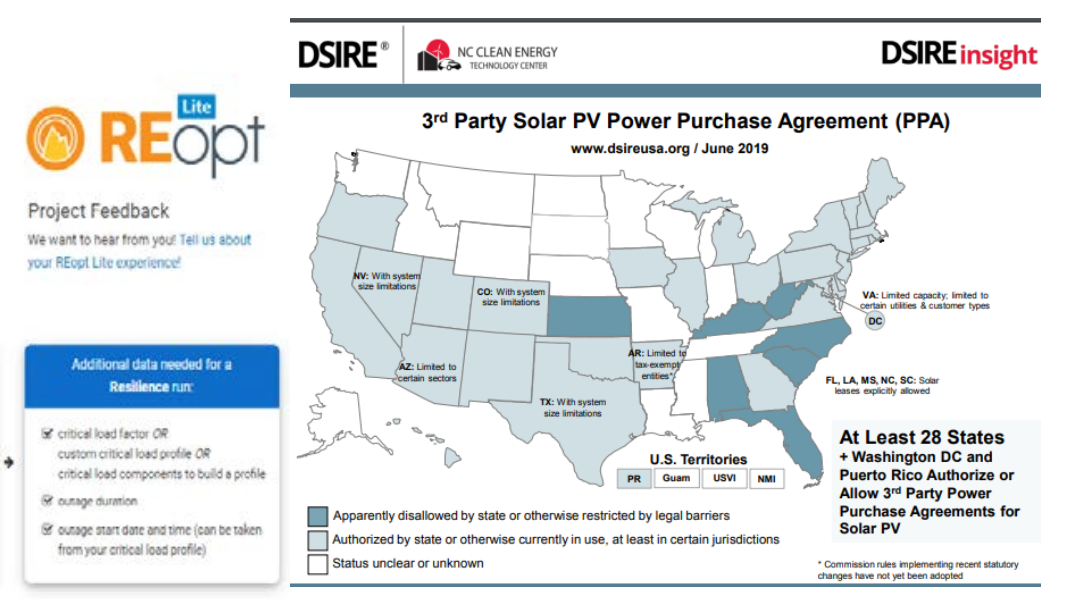




\section{Questions}

- Have HHS, sub-agencies, or individual sites made specific energy and/or resilience goals above and beyond the statutory goals?

- What facilities in HHS may have the highest need for a microgrid?

- After seeing this presentation, where do you feel your knowledge is lacking?

- What are you interested in learning more about? 


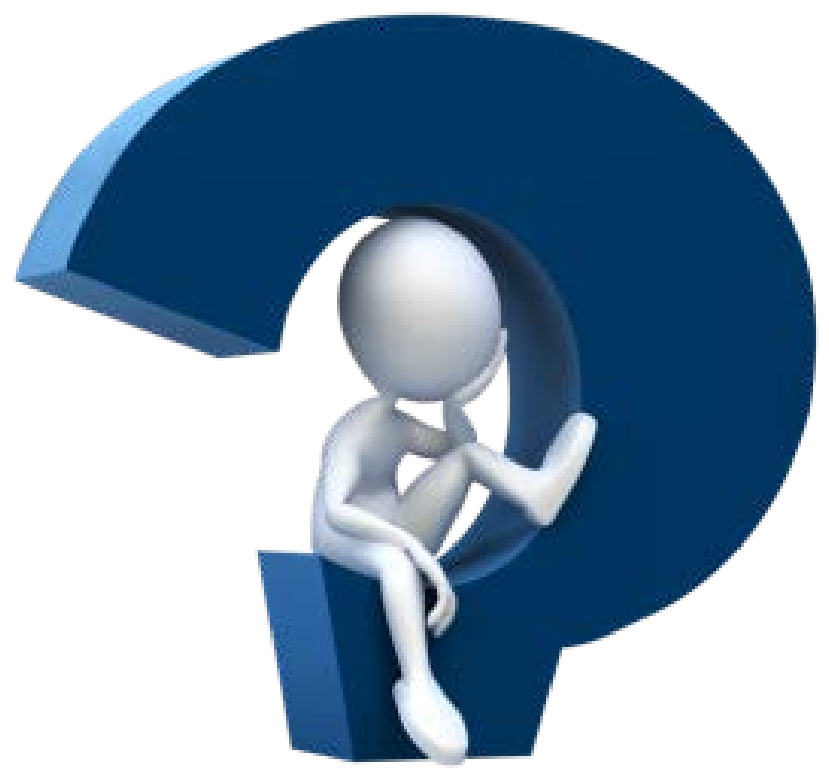

This work was authored by the National Renewable Energy Laboratory, operated by Alliance for Sustainable Energy, LLC, for the U.S. Department of Energy (DOE) under Contract No. DE-AC36-08GO28308. Funding provided by the U.S. Department of Energy Office of Energy Efficiency and Renewable Energy Federal Energy Management Program. The views expressed in the article do not necessarily represent the views of the DOE or the U.S. Government. The U.S. Government retains and the publisher, by accepting the article for publication, acknowledges that the U.S. Government retains a nonexclusive, paid-up, irrevocable, worldwide license to publish or reproduce the published form of this work, or allow others to do so, for U.S. Government purposes. 